\title{
Monsters, Madmen... and Myths: A Critical Review of the Serial Killing Literature
}

\begin{abstract}
Despite the longstanding public and media fascination with the modern 'serial killer', the academic literature is relatively limited. The international field is dominated by individualistic biographical accounts, which offer a highly reductionist and distorted stereotype of the perpetrator, with little opportunity to learn from past cases, or place them within wider sociocultural contexts. Furthermore, there are a profusion of overlapping and confusing terms, confounded by the FBI's social construction of the 'serial killer problem', and perpetuating widespread misleading assumptions. After many years teaching in this area, we are often struck by how these media-driven misconceptions of the serial killer dominate students' knowledge and interest in the topic. This is despite a growing critique of the area in recent years, particularly from within our field of criminology. We seek to debate these issues by exploring some useful cases of serial killing, foregrounding some UK case examples, which are often underexplored. We argue for the need to facilitate scholarly, systematic research to counter the voyeuristic, essentialist narratives within popular media. We also advocate the alternative socio-cultural approach to the study of serial killing, which has emerged in recent years, although been relatively unacknowledged in the international literature to date.
\end{abstract}

Key words: serial killing; multiple homicide; criminology; critique; socio-cultural 


\section{Introduction}

There remains an ongoing and international public interest in the topic of homicide, and of mass and serial killing in particular. The public are increasingly influenced by popular media depictions of the 'deranged' or psychopathic serial killer, and the plethora of 'true crime' accounts that proliferate popular culture (Schmid, 2005). Many of these are sensationalist and voyeuristic, and offer only limited individualized accounts that speculate on 'what makes people kill', with an obsession on the medicalization and pathologization of the killer (Grover and Soothill, 1999; Wilson, 2007). Whilst we note that some recent advances in biosocial approaches to multiple homicide offer the potential to enhance overly reductionist explanations, in this article we highlight the merits of the socio-cultural approach which has, to date, received scant attention in the international literature.

Myths about the 'serial killer' abound, resulting in a distorted and pseudo-psychological focus on individual motivations; an attempt to 'get inside the mind of a killer' that is hindered by the practicalities of research in this field, and by the lack of theoretical engagement and systematic scholarly debate. Reviews of the literature, such as the recent review by Miller (2014) within this journal, focus on individualist and typological accounts of the serial killer, but often fail to review the growing critique of this traditional, and FBI-focused, approach. In this paper we draw attention to the inconsistencies, confusions and myths about serial killers, and highlight some of the limitations, using a range of both 'classic' and more recent case examples. We include some notable UK examples that are often overlooked, as the majority of texts in the field are produced in North America. We draw upon our many years experience of teaching this topic to university students in both criminology and psychology departments in the UK. Over the years we have noted the increasingly voyeuristic interest of students in true crime novels and dramatizations of 
the serial killer (both real and 'imagined') in film and television. This trend has been well documented (Schmid, 2005; Jarvis, 2007), and concerns raised about a growing focus on graphic and sensationalized depictions of death in popular modern culture (Seltzer, 1998). Obviously with no first-hand experience of these extreme violent crimes, such media-based sources have a pivotal role to play in the construction of 'popular criminological knowledge' (Rafter, 2006), both for the worldwide general public and for our students. Whilst the aim here is not to review the specific content of this media genre, it has led us to reflect upon the social construction of the serial killer in the public imagination, and how surprisingly some of these reductionist narratives continue to be upheld in academic representations of the serial killer.

We advocate the need to move away from speculation about individual motivations alone, to consider the broader social, cultural and historical context. We review the emerging critique of more traditional research in the field, and the problematic constructions that emerge of the serial killer. In this integrative review we aim to bring some of this literature together, and argue for the need to rethink the study of the serial killer, and move towards an approach that is more holistic and historically, socially and culturally contextualized.

\section{Definitions, Classifications and Misnomers}

Conceptual confusion and ambiguity are commonplace in the study of homicide generally. The literature on multiple killing is dominated by the work and definitions provided by the Federal Bureau of Investigation (FBI) in the US, originating in the interviews conducted by $\mathrm{FBI}$ agents in the late 1970s and early 1980s. In particular, the 'trichotomy' of multiple killings provided in their Crime Classification Manual, which traditionally distinguished between mass, spree and serial homicide (e.g. Ressler, Burgess and Douglas, 1996): 
1. Mass killing: described as a number of murders (four or more) occurring during the same incident, with no distinctive time period between the murders.

2. Spree Killing: usually described as involving two or more victims, with the murders taking place in two or more locations, within a close space of time (usually no more than 30 days), with no 'cooling off' period.

3. Serial killing: Two or more victims, with the murders taking place in two or more locations, with a 'cooling off' periodi.

Many scholars have, however, noted the difficulties and inconsistencies of these definitions, whose categories are neither exhaustive nor mutually exclusive, leading to confusion in terms of which cases fit within each category, and some cases where considerable overlap exists (Fox and Levin, 2011). The category of spree killing was subsequently removed from the FBI definitions in 2005, after discussions with law enforcement led the FBI to conclude that the category had little practical investigative use and 'created arbitrary guidelines' (FBI, 2005: 9). Nonetheless much confusion still exists among offender profilers and writers in this area as the category of spree killer continues to be referred to in the literature. At the same time the FBI reduced the required number of victims and locations from three to two for cases of serial killing, but again many sources in the literature continue to use the original definition, and you see operational thresholds in the literature for three, four or even five victims before sequential murders are classified as 'serial killings' per se. Another significant change in the 2005 FBI definition was the removal of a requirement for the behavior to be sexually motivated. In theory this should open the definition up to include female serial killers (see Hickey, 2010), although inconsistencies remain in this area, as the $\mathrm{FBI}$ have historically been very reluctant to acknowledge their existence. 
Furthermore, the FBI have been heavily criticized for being too concerned with the frequency and timing of killings, with no emphasis on the motivations of the perpetrator or the context of the killing (Ferguson et al., 2003; Webber, 2009; Waller and Deal, 2010). This in itself tends to imply that the murders must be without clear motivation. An assumption also seems to have been made in this early work that the victims should customarily be strangers. However, this assumption has subsequently been proved to be invalid in many examples (see Brookman, 2005; Prins, 2015). Whilst this concern over conceptual confusion might seem merely an academic debate, there are practical implications in terms of the identification and classification of crimes within these definitions (see Adjorlolo and Chan, 2014, 2015). As Jenkins (1994) outlined, what does and does not fall within our current social construction of 'serial murder' affects our understanding of the prevalence and significance of these crimes. Webber (2009) notes that when the $\mathrm{FBI}$ reduced the number of required victims to two or more in 2005 , this automatically made serial killing appear more significant, greatly increasing the number of cases that fit within this lower victim threshold. For example, many studies now claim an increase in the prevalence of serial killers, particularly in the US, without recognizing the impact of the lower victim threshold, and contributing to increased fear of victimization grossly disproportionate to the real risk posed by such rare and extreme crimes. For example, Miller (2014) cites a rise in active serial killers in the US from 35 in the 1980s, to $200-500$ in recent years, but neither reflects upon the way the FBI have changed the boundaries for inclusion, and therefore define the very nature of the 'serial killer problem', nor acknowledged any of the critical literature which undermines such estimates. Due to the confusion and inadequacy of the FBI definitions, estimates of serial killing vary widely (Keeney and Heide, 1995; Ferguson et al., 2003), and the minority of studies that attempt a systematic analysis often use differing perpetrator populations depending upon the definitions utilized (Jenkins, 1994; Ferguson et al, 2003). Wilson (2007: 34-5) suggests that the original FBI 
definition also has other limitations since it 'masks a variety of criminological debates that are worthy of further consideration.'

There appears to be a need for a universal scholarly definition that highlights the current deficiencies in terms of motivational forces at play. Schechter (2003), for example, notes that the current FBI definition fails to recognize anything about the nature of the crime (something which was seen as essential in the original derivation of the term). Other researchers (including those from within the $\mathrm{FBI}$ ) advocate that the term should not include murders committed for financial gain or revenge, but instead involve sexual motivations (Holmes and Holmes, 2009). Competing terms in the literature such as 'lust murderer' or 'sexually sadistic killer,' whilst recognizing the commonality of sexual motivation in these particular types of murder, also confounds the issues further (Schmid, 2005; Adjorlolo and Chan, 2014). Gresswell and Hollin (1994: 5) also note that such classifications do not 'pick up the more subtle interactions between the killer who may have different motives for different victims and changing motives over time'. Adjorlolo and Chan (2014) provide a comprehensive review of definitions of serial murder, highlighting how detrimental a lack of uniformity and consensus is in the study of serial killing. Consistent with our own concerns, they advocate the use of a definition that does not specify location, motive, offender-victim relationship or context. Significantly they call for a definition that bridges the divide between scholarly and legal uses of the term.

Differing typologies of multiple killers proliferate the literature. They include those put forward from proponents of the FBI offender profiling approach (e.g. Holmes and Holmes, 2009) and opponents to that approach that strive to refine the problematic and restrictive definitions and typologies of the FBI (Schechter, 2003). The most dominant and influential distinction, however, continues to be the FBI's organized/disorganized dichotomy of sexual homicide offenders 
(Ressler, Burgess and Douglas, 1996). This dichotomy is arguably as equally contested in the academic literature as the FBI definitions themselves. Adjorlolo and Chan (2015) note the theoretical and practical utility of classification systems and typologies, although also caution that many classification models still lack empirical validation.

Amid all this conceptual confusion, research is further hampered by both a widely inaccurate popular media construction of the 'serial killer' (Schmid, 2005; Jarvis, 2007), and a reluctance of academic professionals to properly engage with debates around 'evil' and extreme offending in a systematic and scholarly manner (Waller and Deal, 2010; Dearey, 2014). But what do we really know about this group of offenders, who (whilst being statistically uncommon) continue to fascinate the popular imagination?

\section{3. (Mis)Understanding the Serial Killer: Knowns and Unknowns}

Whilst the public and media fascination is enduring, and has resulted in a set of widely held stereotypes about why these killers kill, the academic knowledge is surprisingly limited. Certain serial killers prove undoubtedly very 'newsworthy': attracting considerable media attention, and generating popular public interest (Jewkes, 2011). The public attraction to the darker aspects of human nature, such as torture, cruelty and killing, can be found throughout history, and should be seen as normative rather than aberrantly pathological (Carrabine, 2011). For many people with no firsthand experience of crime, the media becomes our primary source of knowledge formation (Rafter, 2006), and this is even more so with such extreme and rare crimes (Peelo, 2006). The narratives that the media shape regarding serial killers tend, however, to be fairly onedimensional, and perpetuate many of our 'myths' about the psyche of the killer, and the role of offender profiling (and in particular the $\mathrm{FBI}$ ) in apprehending them. In this sense they are also very 
US-centric in their focus. In 1994 Jenkins noted the role of 'true crime' and the impact that had in terms of myth creation; over twenty years later the prevalence and impact of this genre are exponentially greater. Most people's knowledge about serial killing is therefore based on a consistent but flawed narrative; a sensationalist, and simplified stereotype of the organized 'evil' psychopathic killer, who kills randomly without motivation, but who (thankfully) can be easily apprehended using the credible science of profiling ${ }^{\mathrm{ii}}$, restoring our faith in the powers of law enforcement. As Schmid (2005: 79) suggested:

This distorted image of serial murder, moreover, increases the public's level of fear and their sense that society is under siege, partly because the crimes are so vicious, and partly because the victim selection of this type of serial murderer seems so random.

Such prominent representations of serial killers in the media lead to a highly disproportionate fear of victimization. Some of these fears are understandable given the media construction that often graphically highlights the most extreme and shocking aspects such as rape, torture, and sadistic or ritualized killing (Greer and Jewkes, 2005). They also highlight that there is little we can do to protect ourselves from seemingly unmotivated attacks from highly functioning psychopathic strangers; other than rely on higher authorities to protect us from this 'hidden danger' within society. Jenkins (1994) argues that in the US in the 1980s the government, law enforcement and the media exaggerated the number of multiple killers and victims to create a 'moral panic'. They promoted the idea that there was a large number of active serial killers in the US at any one point in time, with thousands of deaths a year, and that this panic made greater federal involvement more acceptable to the general public (Jenkins, 1994; Schmid, 2005). 
The media therefore has an important part to play in the creation of the 'serial killer problem', and it also defines the nature of that concern. Duwe (2005) describes their reporting in terms of a 'circle of distortion', driven by news values, whereby different aspects of serial killing are problematized, with distortions of fact playing a key part. Similarly, Wilson, Tolputt, Howe and Kemp (2010b) note the selective focus of the media; some cases receive vast amounts of media interest, retain news values, and become firmly entrenched in public consciousness. But some cases, despite on the surface seeming just as newsworthy and unsavory, remain relatively unknown and unremembered. Such forgotten cases reveal the 'unknowns' or as Wilson et al. (2010b; 162) term 'absences': 'absences in the literature, absences in knowledge and in current academic theorizing.' Branson (2013) draws similar conclusions about the media neglect of black serial killers in the US. Both studies conclude that such cases are downplayed and forgotten because they do not reinforce the dominant stereotypes about these killers.

Problems also arise when we try to estimate the prevalence of serial killing, in part because of the conceptual and definitional issues raised above, but also because we do not know how many victims and killers go undiscovered. Some serial killers have been found to successfully remain unsuspected and undetected for many years, even decades. For example, drawing on two UK cases, Fred West - whose killings began in 1967 (alone but later with his wife Rose) - did not come to light until 1994; and Harold Shipman's 250+ victims still continue to be 'discovered' years after his suicide in HMP Wakefield in 2004. Also of note is the happenchance manner that such killers are brought to light: in many cases a serial killer is not even suspected, or biases in law enforcement's assumptions about them hinder investigations iii. Despite some earlier work on prevalence in this field, for example, the work of Jenkins (1994), and Gresswell and Hollin (1994) in the US and the UK respectively, these figures are now very dated. As Jenkins (1994) mentioned, the misleading estimates in the 1980s suggested that serial killing in the US had reached epidemic 
proportions. Furthermore, the lowering of the victim threshold has subsequently led to more cases being admissible within the term. Heide and Keeney's (1994) review found 10 different operational definitions in use across studies. Additionally, the academic literature lacks systemic and rigorous research (Dowden, 2005), tending to rely on individualized case studies (Wilson, 2007). Haggerty (2009) comments that despite the volume of individual cases explored, and the ongoing fascination with these killers, they remain largely unknowable and unimaginable.

Research suggests that many of the dominant 'truths' about the serial killer are at best inconsistent and, in many cases, distortions and 'untruths'. The US media and the literature produced by former FBI agents present the view that these killers can be easily categorized, that the emergent typologies are valid and meaningful, and that profiling provides a credible tool of investigation leading to the capture of the offender. Such social constructions seem to fulfill a purpose in terms of convincing the public that there is a significant risk, that the offender is outside our established normality, and that the danger is unpredictable due to the motiveless targeting of strangers (or if not motiveless, that the motive is unimportant). It then validates the role of law enforcement and fosters trust in investigative techniques. All of this is, however, misleading. Examples show us that often these killers do not fit the FBI categories, do not fall into strictly organized and disorganized offenders, do not tend to kill without any motivation (but those motivations also may not fit into clear typologies and may defy easy understanding), and victims are often not chosen at random and may well be people the offender has an existing relationship with (e.g. patient, tenant, lover, child). Additionally, this narrative is misleading in terms of what the 'science' of profiling can achieve, and downplays the notable failures of such methods (Wilson, Jackson and Rana, 2010a). 
These narratives also lead us to believe that serial killers are almost exclusively white and male, and that (where a motivation is highlighted) it is sexual in nature. Research, however, shows that these are also misleading, and that serial killing is much more diverse than this construction has us believe (Jenkins, 1994; Bartels and Parsons, 2009). In the following section we continue to critically explore some of these widely held 'truths' about the serial killer, aided by some brief case illustrations.

\section{Identification of the Serial Killer: Opportunities Missed}

Some of the prevalent myths about the serial killer can blind us to the diversity of this group of offenders, and in some cases it has also hindered their identification and capture. Even when practitioners who come into contact with these individuals have raised suspicions, they have often been dismissed with devastating consequences, leading to further innocent deaths. In this section we briefly explore some case studies to illustrate who we have not been looking for, and what dilemmas and difficulties fundamentally serve to challenge the identification that a serial killer is active. In reality, cases show that these killers defy many of these long-held expectations, and that these preconceptions can be damaging to those who may come into contact with the perpetrators, with tragic results.

The most pervasive construction of the serial killer is of a white male, often acting alone. There are, however, numerous examples of serial killers working together, both same-sex and mixedsex partnerships, and these are thought to account for up to $25 \%$ of multiple killings (Hickey, 2010; Fox and Levin, 2011). Whilst the literature has gradually therefore become more accepting of a female co-perpetrator being involved in the killings, there is still the tendency to assume that she is more passive, or herself a victim of a dominant and abusive male partner (Morrissey, 2003; 
Gurian, 2011). Female serial killers have also played into this construction themselves by claiming that their involvement was involuntary and born out of fear (see, for example, the case of Myra Hindley in the UK, and Karla Homolka in Canada), or denying any knowledge or involvement in the crimes whatsoever (as, for example, in the UK, the continuing silence of Rosemary West over her involvement and awareness of the deaths of 11 young women, including her own child Heather, despite many of the murders taking place and being buried in her own home) $)^{\text {iv }}$. It is also interesting to note the support such women have received, even in light of considerable evidence that challenges this construction of them as blameless, passive or unaware. For some, the acknowledgement of a female serial killer, particularly an agentic perpetrator rather than a passive bystander, is too problematic for our enduring stereotypes of women as non-violent, nurturing, and incapable of such orchestrated cruelty (Morrissey, 2003; see also Downing, 2013).

In recent years there has, however, been a greater recognition of female serial killers. Recent studies have estimated that about $16 \%$ of serial killers are women (Hickey, 2010; Harrison et al., 2015). Unfortunately, this has also led to the creation of further misleading stereotypes whereby we either fail to accept their planned killings, and/or sadistic pleasure in the violence. We tend to reconstruct these women as victims of a male-dominated hetero-patriarchal society (Morrissey, 2003). Alternatively, we reconceptualize the women themselves as 'non-women'; doubly deviant in the sense that they transgress not only our moral boundaries but also our views of what it means to be a woman (Birch, 1993; Jewkes, 2011). The media has been instrumental in these various constructions of violent women. For example, Aileen Wuornos, who killed seven men in the US between 1989 and 1990, is sometimes portrayed as a sadistic thrill-seeking killer, the first female serial killer to be acknowledged by FBI profilers (Gurian, 2011). But she is also often constructed as a victim of abuse, who subverts the violence done to her in the past by men through her vengeful (and symbolic) killing of her male clients (Hart, 2002; Smith, 2005). These 
interpretations are foregrounded in the 2003 Hollywood film adaptation of her life Monster (Downing, 2013). Whilst we accept (and arguably glamorize) the image of the sadistic, thrillseeking sexually motivated male serial killer, this stereotype is often much too incongruent to accept for their female counterparts.

The autonomous female serial killer is someone we tend to find more difficult to reconcile, and we strive to find meaning seemingly as a way to explain their anomalous appearance among male serial killers. Female serial killers are therefore (when they cannot easily explained as victims of male violence) assumed to kill for financial gain, again playing into socially constructed narratives of the 'the 'black widow' (Morrissey, 2003; Gurian, 2011). When a woman does not fit into any of these accepted constructions we do not know how to explain her, and find her existence threatening. We see glimpses of this in well-known cases of women who kill in conjunction with their lover - estimates suggest that one third of female serial killers do not act alone (Kelleher and Kelleher, 1998; Harrison et al., 2015) - who seem to enjoy similar sadistic sexual pleasure from the killing. Arguably Myra Hindley became more iconic and vilified than lan Brady for her involvement in the Moors Murders (in Northern England, 1963-1965) because her existence challenged our narratives of accepted femininity (Birch, 1993; Morrissey, 2003). Similarly, in Canada in the case of Karla Homolka and Paul Bernado, who were responsible for the rape and murder of three women between 1990 and 1992, the police seemed more than willing to accept Karla's narrative of an abused wife, terrified of her husband and forced into involvement in the rape and murder of her own sister, although the couples' videotapes of the crimes revealed her active encouragement and participation (Morrissey, 2003).

The behavior of the lone female killer, whose motives seem to defy explanation - they cannot be constructed as killing for profit or greed, do not kill for self-preservation, or revenge - can be 
particularly difficult to accept. This is evident in some of the competing representations and narratives regarding Aileen Wuornos, and also in the more recent legal and media reaction in the UK case of Joanna Dennehy. Dennehy killed three men (and attempted to murder two others) over the space of 10 days in $2013^{v}$; the media coverage focused on the premeditation of the crimes, the light-hearted way she joked about them to the police, and her lack of remorse. Whilst these features would not seem too noteworthy with a male killer, the agency and reports of her 'killing for fun' are incongruent with our perception of the female killer. On her conviction in 2014 she was branded 'psychopathic' and became one of only three women in the UK to be given a 'whole life' tariff. ${ }^{\text {vi }}$ Recent, more large-scale and systematic studies are starting to highlight that female serial killers are not that uncommon and are diverse, killing for a variety of reasons including money and revenge, but also power, excitement and fame (Harrison et al., 2015).

It is not just the narrative of female multiple / serial killers that is problematic for our limited and flawed understanding of the phenomena. The assumption of a white perpetrator has also been found to be particularly pervasive and difficult to challenge, again even in the face of evidence to the contrary. Walsh (2005) documents 90 black serial killers from 1945 to 2004 in the US. Hickey (2010) argues that given that black people only make up $13 \%$ of the US population, and black serial killers make up $22 \%$ of serial killers, they are disproportionately more likely to be black than white. Both Walsh (2005) and Branson (2013) argue that the black serial killer is less newsworthy even when their deeds are just as shocking and grisly as their white counterparts, and/or their body count as high. Branson (2013) focuses on the case of Harrison 'Marty' Graham who killed seven women between 1986 and 1987, yet remains relatively unknown and unacknowledged. In contrast Gary Heidnick, who was also arrested in Philadelphia in 1987 for killing two victims, has received countless media depictions, forming part of the inspiration for the character 'Buffalo Bill' in The Silence of the Lambs (1991). Branson (2013) argues that whilst society and the media 
expect violent offenders to be disproportionately black, this is not the case with the serial killer, who we assume to lack the intelligence and methodological orchestration of the psychopathic killer. The racial bias of the $\mathrm{FBI}$ and their failure to acknowledge and profile non-white serial killers has been widely noted (see Walsh, 2005). As Branson (2013: 14) concludes 'the myth of the nonexistence of black serial murderers creates a metaphorical cloak that permits their predations to go unnoticed.'

Branson's discussion of the anonymity of black serial killers due, in part, to public and professional assumptions about psychopathic perpetrators, leads us to one of the key challenges in the study of serial killing - the presence or absence of psychopathology. In these cases that defy public explanations, further reinforced by the perception that they are relatively motiveless crimes, we seek to find some understanding and psychological comfort in individualistic explanations (Zimbardo, 2009). We often revert to reductionist understandings that the perpetrator must be 'mad', and in the absence of collaborating evidence, we resort to the assumption of psychopathy. Psychopathy is now a somewhat outdated and discredited psychiatric label, giving way to the reconceptualization of psychopathy into distinct personality disorders from the 1960 s onwards. It still, however, remains the dominant discourse about the nature of the serial killer, and has some convenient consequences in terms of how we rationalize and deal with this group of offenders (Prins, 2013). For example, the psychopathic are seen as less deserving of sympathy, are usually deemed legally sane, and punished rather than rehabilitated or treated. The serial killer also remains something firmly outside our moral universe; the label serves to dehumanize the perpetrator, fitting them into dominant narratives about 'evil' whereby the perpetrator of evil actions must themselves be evil (Eagleton, 2010). This, we argue, presents us with a moral and normative conclusion, but one that does not further aid our understanding of the crime, the perpetrator, or the society in which such behavior occurs. 
Often when the serial killer comes to trial the defense and prosecution arguments focus heavily on the presence or absence of mental disorder. Although the medico-scientific basis of psychiatry would lead those outside the field to believe that this is something that can be easily and confidently established, diagnosis in such cases is rarely easy and uncontested. Furthermore, there are many cases of serial killers attempting to argue 'insanity' (sometimes referred to as 'malingering') to mitigate their sentence, or escape the death penalty. In the US, where 31 states retain the death penalty, this has been even more pronounced.

In the case of Anders Breivik, he himself defended his sanity throughout his televised trial in 2012, whilst the prosecution argued to have him pronounced insane. Breivik's attacks began on 22 July 2011 when he bombed central Oslo, Norway, killing eight people. Later that same day he changed tactics and opened fire on a youth camp on the island of Utøya (25 miles northwest of Oslo), killing 69 people, mostly teenagers. His attacks were meticulously planned, and his 'manifesto' for the violence - where he warned of the dangers of multiculturalism and the threat of Muslim immigration to Norway - had been emailed prior to the attacks. He admitted killing the 77 victims, and saw his trial as a platform for his cause. Arguments at the trial focused on whether Breivik was a paranoid schizophrenic, based on the claims made in his manifesto and his belief that his actions were justified in the face of the threat of multiculturalism (he refused to plead guilty). The first psychiatric team appointed by the court upheld this conclusion, but a second team concluded that he was sane. The presiding judge said that the court considered that Breivik was suffering from 'narcissistic personality characteristics' but not from psychosis. The sentence she imposed was one of 'preventive detention', a term used for offenders considered to be dangerous to society. It seems doubtful that Breivik will ever be released. 
Uncontested psychiatric diagnosis in these cases is therefore unlikely, and as seen in the case of Breivik psychiatric teams often disagree as to the existence, nature and/or extent of mental disorder. Cases where perpetrators have been (conveniently) diagnosed prior to their homicidal actions are scarce. In some cases, we are denied careful psychiatric evaluation after capture due to perpetrator suicides. These are notably likely in mass killings whereby the offender turns their weapon upon themselves at the end of the attack, either as part of their initial plan, or to evade capture. For example, Thomas Hamilton who killed 17 (mostly young children) in Dunblane, Scotland in 1996 before killing himself, or the perpetrators of 'school shootings' in the US, such as at Columbine in 1999, or Virginia Tech in 2007.

Some of our most famous serial killers have also denied us further elucidation of their motivations or state of mind by killing themselves whilst in custody. Notable examples in the UK include both Harold Shipman and Fred West. In cases of mental illness, as opposed to the broader term mental disorder (which would include conditions such as psychopathy, or personality disorders), symptoms may be more obvious, but if psychoses (or other serious mental illness) has developed in the perpetrator they rarely make good candidates for a serial killer who must have the mental capacity to plan their killings and evade apprehension. Serial killers are therefore infrequently disordered in mind, and more likely to be disordered in conduct (Fox and Levin, 2011), although exceptions to this do exist (Prins, 2015). Even where the evidence seems to support the case that the defendant was mentally disordered at the time the killings were committed, barriers still exist in terms of the difficulties and inconsistencies of the law, and significantly in terms of competing public and political concerns about justice 'being seen to be done'.

A notable case in the UK is that of Peter Sutcliffe (the 'Yorkshire Ripper'), which attracted such notoriety and media interest that some of the key issues concerning the diminishment, or 
otherwise, of his mental responsibility for his acts tended to be overshadowed. Sutcliffe killed 13 women between 1975 and 1980 (although a further seven escaped). Initially these victims were prostitutes but he then went on to kill other women, causing widespread panic in the North of England during this time. When he was eventually captured and interviewed he professed that he was acting in accordance with a God-given mission to rid the world of prostitutes, and subsequently he was diagnosed with paranoid schizophrenia; a diagnosis that was upheld by several very experienced forensic psychiatrists. Sutcliffe's case highlights in compelling fashion a number of relevant issues. Despite unanimous agreement from the psychiatrists for both the prosecution and defense, the judge decided to put the issue of Sutcliffe's mental responsibility for his acts to a jury. The fact that he had actually committed the murders was not being disputed merely his criminal responsibility for so doing. But it may well also be the case that given the notoriety of this case in particular the judge was aware that a reduced conviction of manslaughter would be unpopular with the UK public, compared to the mandatory life sentence attached to a murder conviction.

The outcome of the trial was that Sutcliffe was judged to be legally sane, and sentenced to life imprisonment. Whilst in prison his paranoid schizophrenia deteriorated, and after attempts on his life by other prisoners, he was subsequently moved to Broadmoor high security hospital in 1984, where he is still detained. The manner in which the psychiatric evidence was commented upon in the press during the trial revealed the societal ambivalence towards the intervention of psychiatry in criminal cases. The adversarial system of justice does not lend itself readily to the deliberation of complex issues of intent and motivation. So even in a case where the psychiatric evidence was highly persuasive and agreed upon, a mismatch between the psychiatric complexities of the case, and the public's understanding of mental illness and desire for retribution, caused additional difficulties. 
In cases of psychopathy (or current terms such as anti-social or narcissistic personality disorders), one is unlikely to receive a diagnosis until the behavior has been sufficiently noticeable and disruptive to reach the attention of the authorities. In this respect the label is often a term of convenience (see Manning 2006 and Charland, 2006), and is tautological in the sense that you are deemed to be psychopathic (or personality disordered) because of your violent and extreme behavior, which itself is only explained in terms of you being a psychopath (Prins, 2013). In the absence of mental illness in a serial killer, a conclusion of 'evil' is often assumed as an explanation by the media. But precise psychiatric diagnoses in these cases are often inherently problematic, as Dennis Nilsen's case illustrates.

Nilsen admitted having sex with, and killing, fifteen young men in England between 1978 and 1983. After their death he kept the bodies for weeks or even months, storing the corpses away whilst he went to work and getting them out again upon his return. He is known to have continued to have sexual activity with the corpses after death, and to keep the bodies until they started to decay. He subsequently dissected, boiled and burned their bodies in order to dispose of them, and was only caught when he flushed pieces of human flesh down the toilet causing the drains to block. At trial the defense argued that his legal culpability for the crime be mitigated due to mental disorder; however, the jury refuted his plea. He was convicted of murder and sentenced to life imprisonment with a minimum recommendation that he serve 25 years, and he remains in prison to date. Unlike Sutcliffe's case, there had not been unanimity of view by the three psychiatrists who assessed his case. The behavior here was so unimaginable and beyond understanding, it was assumed that there must be something psychiatrically wrong with Nilsen, but clearly establishing what this was proved problematic even for a team of psychiatric experts. Cases like Nilsen's provide us with contradictions and questions, and again challenge some of our 
preconceptions about the serial killer. He continued his normal life as a civil servant, and his crimes only came to light through accident rather than an investigation. His victims were young, often homeless homosexual men - no one realized they were victims, or suspected that a killer was active. He seems to have dispassionately disposed of the bodies, but also seemed to be conflicted and lonely (Masters, 1995), needing to keep the bodies as long as possible. The label of psychopath in this and other cases belies the complexities, and serves to dehumanize and dismiss the perpetrator, doing little to foster further understanding of these crimes.

Contrary to popular perceptions, serial killers may even be in positions of trust, and use that position to their advantage to gain access to vulnerable victims, whilst blinding practitioners to their guilt by their status within society. Reviewing the cases of serial killers reveals a significant proportion that, contrary to our beliefs, do not target random strangers at all. The UK case of Harold Shipman illustrates this. Although we still do not know the full extent of Shipman's victims, he is the most prolific known serial killer in British history (Gunn, 2010), arguably the most prolific modern serial killer worldwide, claiming at least 215 victims (with estimates suggesting as many as 260 victims) (Soothill and Wilson, 2005). He is thought to have started killing soon after leaving medical school in 1971, at the age of 25 , but his crimes were not discovered until a relative of one of his victims raised suspicions in 1998. His victims were of middle age or above; after examination in the doctor's surgery, he would visit them at their home to give them an injection, which would be a lethal dose of diamorphine. He would tell relatives that they had suffered a heart attack, and encourage cremation of the body to prevent later exhumations. It was the failure to convince some relatives of this, along with a crudely forged will, that led to suspicions and his eventual conviction of 15 deaths in 2000 . This led to an extensive inquiry which reported a number of 'warning signs' that should have been noticed. For example, the excessive number of death certificates he required to be issued. It was concluded that his motivations were not 
primarily financial, that although he had forged a will to benefit from one of his victims this was an exception. Shipman refused to co-operate in the investigations, refused to speak to professionals, and refused a psychiatric defense, maintaining that he was not guilty. As Shipman committed suicide in 2004 , whilst serving a sentence of life imprisonment, his case remains somewhat of an enigma. Despite claims that he could be cold and aloof by his colleagues, his patients described him as a good and caring doctor, who was well respected (Gunn, 2010). His position allowed him the access and the means to commit his killings, and protected him from suspicion for nearly 30 years.

Soothill and Wilson (2005: 687) suggest that the public, professionals, and academics are reluctant to confront such cases as it 'upsets our comfort zone too much'. He does not readily fit our preconceptions of a serial killer at all, but Shipman is not an anomaly. Although Shipman tends to be presented as a unique exception, studies have confirmed that this is not the case. There are numerous examples worldwide of such 'caregiver associated killing' (Yorker et al., 2006). This includes, in the UK, the well-known case of nurse Beverely Allitt; convicted in 1993 for killing four infants under her care, as well as a further nine counts of attempted murder and Grievous Bodily Harm (GBH). An extensive inquiry in this case also revealed considerable shortfalls and mistakes, including medical evidence of irregularities that if viewed together would have alerted authorities to the deaths, but were not connected until much too late.

It could be argued that such cases challenge our feelings of relative safety - that we can readily identify a serial killer, that they are not people in positions of trust, or people we know, and that they can be easily apprehended by law enforcement. The silence and lack of academic and professional debate in this area can, however, be damaging (Soothill and Wilson, 2005), and there are lessons to be learned from past omissions and mistakes. A culmination of critical commentary 
on the deficiencies and gaps within the traditional serial killer literature has recently promoted a more historically and contextually sensitive approach to the topic, which we will now briefly discuss.

\section{Towards a Socio-Cultural Approach}

The dominant approach to the study of multiple killing, adopted and advanced by the FBI, as well as other highly influential sources of information within the realms of mass media, supports an understanding and response principally fixed at an individual level (see, for example, Yardley and Wilson, 2015). This perpetuated focus upon the individual offender has generated a number of essentialist stereotypes concerning the killer's disposition or 'character' (Dietz, 1996); convenient simplifications and logical fallacies; 'absences' in our understandings; 'untruths'; biases; inconsistencies and confusions; glamorizations; and dead-end debates (Dearey, 2014). Crucially, detailed examination of the wider social, cultural and historical contexts which may generate, shape and facilitate such behaviors, and which problematizes the reductionist 'traditional' approach, has largely been unnoticed or ignored (Haggerty, 2009).

A number of theorists have successfully begun to broaden the focus to examine factors beyond those located on the level of the individual which have largely stemmed from essentialist psychomedico traditions (see Bauman, 1989; Grover and Soothill, 1999; Leyton, 2003; Wilson, 2007; Haggerty, 2009). This small, yet cogent, body of work has highlighted how particular elements of modern society and culture frequently underpin and frame acts of serial killing of all varieties, and have accordingly begun to provide greater nuance to our understandings of this issue. In doing this, such research has begun to outline how the nature of particular societies may create accommodating circumstances, incentives and opportunities for serial killing. 
The authors argue, therefore, that in order to develop a more robust framework for the study of serial killing, more research is required in order to build upon the broader focus and insights already advanced by the aforementioned theorists. Rather than viewing the nature of the act and actor of serial killings as being a-cultural and a-historical, it is necessary to sufficiently place these crimes (as well as our understandings) within their own particular context, to synthezise a micro and macro approach, and to identify the underlying factors involved in shaping the act's manifestation. Accordingly, more focus needs to be given to ancillary elements such as the significance of victim selection and the social creation of cultures of denigration and marginalization wherein particular social groupings lack protection and become vulnerable to predation. As noted by Wilson (2007: 23):

Those who want to kill repeatedly can only achieve this objective when the social structure in which they operate allows them to do so by placing value on one group to the detriment of others.

Similar ideas of social inequality being an important underpinning of serial killing have been raised by both Bauman (1989) and Grover and Soothill (1999). Haggerty (2009) also pinpoints a number of other distinctly modern phenomena that help fashion sequential killing in modernity's own self-image. Such factors may include (but are in no ways limited to) the greater social anonymity as a consequence of the rise of urbanization; the growth of mass media, rise of celebrity culture and the fast track to fame through multiple killing; and a cultural means/end rationality which, when taken to its extreme, can be invoked by individuals to justify almost any act. 
By highlighting important macro-level contextual factors that both underpin and may help pattern acts of serial killing, this socio-cultural framework considers the issue not as a cultural abnormality, or the actors as some kind of human aberration, but instead sees the phenomenon as a regrettable social by-product of our times and culture. Accordingly, when adequately placed within context, such acts move from being perceived as 'motiveless' and incomprehensible to being, in many ways, 'rational' and comprehensible. Rather than being explained as the result of individual pathology, such behaviors can often be seen as individual responses or solutions to wider social or cultural issues. Within capitalist cultures which maintain high social incentive for status and power, and inadequately satisfy the needs and desires of all, acts of serial killing may perhaps be viewed as one way to 'cheat the system' and reap rewards that social conformity to conventional standards of morality and normality often do not yield. Individuals who choose such paths, who transgress society's structural constraints and boundaries, 'are not categories, they are not types, they are possibilities' (Jenks, 2003: 185, italics added).

By broadening the framework within which to study and understand this phenomenon, it appears that various, and changeable, social, cultural and historical contexts may be consequential in the manifestation and facilitation of particular patterns of serial killing. A socio-cultural approach therefore opens up the study of serial homicide to a wealth of academic input from diverse disciplines previously overlooked giving it the holistic, humanistic and eminent status it requires. In doing this, the study may help identify unhealthy aspects of culture and society, highlight the need for wider social responsibility and inclusion, and help put to rest the 'worn-out', repetitive discourses that have inadequately advanced our understanding of this phenomenon.

That is not to say that there is not considerable merit in combining micro and macro perspectives to further advance a broader and more holistic understanding of these phenomena. It is worth 
noting that there have been some valuable advances made within the field of biosocial criminology in recent years, supporting the view that biological correlates may play a role in the complex manifestations of serial killing behaviors (see for example, Morgan and Lilienfield, 2000; Ogilvie, Stewart, Chan and Shum, 2011). Whilst more robust and standardized psycho-medico analysis on future cases is necessary, research suggests that the inclusion of such knowledge would augment a more nuanced framework for understanding serial killing phenomenon (Allely, Minnis, Thompson, Wilson and Gillberg, 2014). This would therefore allow for an integration of both individualistic and socio-cultural insights, thus examining the perpetrator and their crimes within their context.

\section{Conclusions}

In conclusion this review of cases and literature reveals that many of our deeply entrenched beliefs about the serial killer, perpetuated by not only the media, but often by 'pop psychology', and law enforcement, are deeply flawed. They instill us with the stereotype of the white, male, motiveless or sexually motivated killer, who targets random strangers but can be apprehended by the science of profiling. As other critics have argued, this selective narrative about serial killing can be problematic and even dangerous (Jenkins, 1994; Soothill and Wilson, 2005; Wilson et al., 2010b; Branson, 2013), and can blind us to the diversity of the serial killer. In some notable cases this has even led to prolonged investigations, misleading profiles, and further deaths. Contrary to popular belief the serial killer comes in many forms; they may be female, black, elderly, they may act alone or in pairs or groups, they may kill for a variety of motivations (and this may vary over time), and they may even be someone the victim knows (sometimes even a partner, trusted nurse or doctor, or family member). Mental disorder may or may not be present, and although a label of 
'personality disorder' or 'psychopathy' may be all too readily applied to these individuals, in many cases these may merely cloud our understanding further. The media influence on our social construction of the serial killer affects not just our understanding of the phenomena, but is interestingly also reflected in the way that these perpetrators view and construct themselves (Bartol and Parsons, 2009).

The dominance of 'true crime' in an area surprisingly devoid of academic debate leads to misleading perceptions about the serial killer. These reductionist and sensationalist narratives, whilst arguably catering to the voyeuristic demands of the public, serve to hide the complexities of such cases. The serial killer is clearly more diverse than we are led to believe, and furthermore the criminal justice system can also be ill equipped to deal with these cases that bring up inherent dilemmas and challenges. This is noted in terms of establishing the extent of serial killing, especially given the conceptual confusion that remains; and apprehending these elusive perpetrators, complicated by the widespread assumptions about who a serial killer actually is. Furthermore, issues such as mental responsibility and motivation are complex and contested, and can often provide a mismatch between psychiatry and the adversarial system of justice.

In advancing a new framework for the study of multiple/serial killing that seeks to unify both micro and macro analysis, the authors attest that more value and appreciation must be given to socio-cultural insights for the field to advance beyond its present stagnation. Yet, although the paper is primarily intended to promote the much neglected macro (socio-cultural) aspect of this framework, it does not seek to wholly disregard the value added by micro (individualistic) analysis. By advocating a micro and macro synthesis, we remain open to the value of more integrative (i.e., bio-psycho-social etc.) frameworks. 
The dominant popular and individualist explanations that rely exclusively on biographical accounts of these killers, and seek to pathologize the killer rather than face broader societal and cultural explanations, have become a hinderance to this field of study (Grover and Soothill, 1999). Whilst criminologists have been largely reluctant to engage in a scholarly and systematic debate on the serial killer, or on human 'evil' as a whole (Dearey, 2014), there is clearly a need for more research and theoretical discussion within the field.

\section{References}

Allely, C. S., Minnis, H., Thompson, L., Wilson, P. and Gillberg, C. (2014)

'Neurodevelopmental and psychosocial risk factors in serial killers and mass murderers', Aggression and Violent Behavior, 19(3): 288-301.

Bartol, R. and Parsons, C. (2009) 'The social construction of a serial killer', Feminism and Psychology 19(2): 267-280.

Bauman, Z. (1989) Modernity and the Holocaust, Cambridge: Polity Press.Birch, H. (1993) 'If looks could kill: Myra Hindley and the iconography of evil' in H. Birch (Ed) Moving Targets: Women, Murder and Representation (p.p. 32-61), London: Virago Press.

Branson, A.L. (2013) 'African American serial killers: Over-represented yet underacknowledged', The Howard Journal, 52(1): 1-18.

Brookman, F. (2005) Understanding Homicide. London: Sage. 
Canter, D. and Youngs, D. (2003) The Investigative Psychology of Serial Killing, London: Ashgate.

Canter, D. V., Alison, L. J., Alison, E., \& Wentink, N. (2004). The organized/disorganized typology of serial murder: Myth or model?', Psychology, Public Policy, and Law, 10: 293-320.

Carrabine, E. (2011) 'Images of torture: culture, politics and power', Crime, Media, Culture, 7(1): $5-30$.

Charland, L.C. (2006) 'Moral nature of the DSM-IV Cluster B Personality Disorders', Journal of Personality Disorders, 20(2): 116-125.

Dearey, M. (2014) Making Sense of Evil: An Interdisciplinary Approach, Basingstoke: Palgrave Macmillan.

Dietz, M. L. (1996)'Killing Sequentially: Expanding the Parameters of the Conceptualisation of Serial and Mass Killers', in T. O'Reilly-Fleming (Ed) The Study of Serial Murder: Theory, Research and Policy (p.p. 109-118). Toronto: Canadian Scholars Press.

Dowden, C. (2005) ' Research on multiple murder: Where are we in the state of the art?' Journal of Police and Criminal Psychology, 20(2): 8-18.

Downing, L. (2013) The Subject of Murder: Gender, Exceptionality, and the Modern Killer, London: The University of Chicago Press. 
Duwe, G. (2005) A Circle of Distortion: The Social Construction of Mass Murder in the United States, Western Criminology Review 6(1), 59-78.

Eagleton, T. (2010) On Evil, London: Yale University Press.

FBI (2005) Serial Murder: Multi-disciplinary perspectives for investigators, US Department for Justice. Available at: http://www.fbi.gov/stats-services/publications/serial-murder [Accessed 20 May 2015]

Ferguson C, White DE, Cherry S, Lorenz M and Bhimain Z (2003) Defining and classifying serial murder in the context of perpetrator motivation. Journal of Criminal Justice 31: 287-92

Fox, J.A. and Levin, J. (2011) Extreme Killing: Understanding Serial and Mass Murder (2 ${ }^{\text {nd }}$ ed.), London: Sage.

Greer, C. and Jewkes, Y. (2005) 'Extremes of otherness: Media images of social exclusion', Social Justice 32(1): 20-31.

Gresswell, D.A. and Hollin, C.R. (1994) Multiple Murders: A Review. British Journal of Criminology, 34: 1-14

Grover, C. and Soothill, K. (1999) British serial killing: Towards a structural explanation. The British Criminology Conferences: Selected Proceedings, Volume 2. Leicester: BPS. 
Gunn, J. (2010) 'Dr Harold Frederick Shipman: An enigma', Criminal Behaviour and Mental Health, 20: $190-198$.

Gurian, E.A. (2011) 'Female serial murderers: Directions for future research on a hidden population', International Journal of Offender Therapy and Comparative Criminology, 55(1): 2742.

Haggerty, K.D. (2009) Modern serial killers, Crime Media Culture, 5(2): 168-187.

Harrison, M.A., Murphy, E.A., Ho, L.Y., Bowers, T.G. and Flaherty, C.V. (2015). 'Female serial killers in the United States: Means, motives, and makings', The Journal of Forensic Psychiatry and Psychology, 26(3): 383-406.

Hart, L. (2002) 'Surpassing the word: Aileen Wuornos', Women \& Performance, 13(1): 61-88.

Hickey, E. (2010) Serial Murderers and their Victims (5 ${ }^{\text {th }}$ ed.), Belmont, CA: Thomson/Wadsworth.

Holmes, R.M. and Holmes, S.T. (2009) Profiling Violent Crimes: An Investigative Tool (4 ${ }^{\text {th }}$ ed.), London: Sage.

Jarvis, B. (2007) 'Monsters Inc.: Serial Killers and Consumer Culture', Crime, Media, Culture, 3(3): 326-44.

Jenkins, P. (1994) The Social Construction of Serial Homicide, New Brunswick, NJ: Transaction. 
Jenks, C. (2003) Transgression, London: Routledge.

Jewkes, Y. (2011) Media and crime ( $2^{\text {nd }}$ ed), London: Sage.

Keeney, B.T. and Heide, K.M. (1995) 'Serial murder: A more accurate and inclusive definition', International Journal of Offender Therapy and Comparative Criminology, 39(4): 299-306.

Kelleher, M.D. and Kelleher, C.L. (1998) Murder Most Rare: The Female Serial Killer, Westport, CT: Praeger.

Lee, C.A. (2011) One of Your Own: The Life and Death of Myra Hindley, Edinburgh: Mainstream Publishing.

Leyton, E. (2003) Hunting Humans: The rise of the Modern Multiple Murderer (2 ${ }^{\text {nd }}$ Ed.), New York: Carroll and Graf.

Manning, N. (2006) 'DSM- IV and dangerous and severe personality disorder: An essay', Social Science and Medicine, 63(7): 1960-1971.

Masters, B. (1995) Killing for Company: The Case of Dennis Nilsen, London: Random House.

Masters, B. (1997) "She Must Have Known": The Trial Of Rosemary West, London: Random House.

Miller, L. (2014) 'Serial killers: I. Subtypes, patterns and Motives', Aggression and Violent Behavior, 19: 1-11. 
Morgan, A. B. and Lilienfeld, S. O. (2000) 'A meta-analytic review of the relation between antisocial behavior and neuropsychological measures of executive function', Clinical Psychology Review, 20(1): 113-136.

Morrissey, B. (2003) When Women Kill: Questions of Agency and Subjectivity, Abingdon: Routledge.

Ogilvie, J. M., Stewart, A. L., Chan, R. C. and Shum, D. H. (2011) 'Neuropsychological measures of executive function and antisocial behavior: A meta-analysis', Criminology, 49(4): 1063-1107.

Peelo, M. (2006) 'Framing homicide narratives in newspapers: Mediated witness and the construction of virtual victimhood', Crime, Media, Culture, 2(2): 159-175.

Prins, H. (2013) Psychopaths: An introduction, Hook: Waterside Press.

Prins, H. (2015) Offenders, Deviants or Patients? Explorations in Clinical Criminology ( $5^{\text {th }}$ ed), Hove: Routledge.

Rafter, N. (2006), Shots in the Mirror: Crime Films and Society ( $2^{\text {nd }}$ ed.), Oxford: Oxford University Press.

Ressler, R.K., Burgess, A.W. and Douglas, J.E. (1996) Sexual homicides: Patterns and motives, New York: The Free Press. 
Schechter, H. (2003) The Serial Killer Files: The Who, What, Where, How, and Why of the World's Most Terrifying Murderers, New York: Ballantine Books.

Schmid, D. (2005) Natural Born Celebrities: Serial Killers in American Culture, Chicago, IL: University of Chicago Press.

Seltzer, M. (1998) Serial Killers: Death and Life in America's Wound Culture, New York: Routledge.

Smith, A. (2005) 'The "Monster" in all of us: When victims become perpetrators', Suffolk University Law Review, 38: 367-394.

Soothill, K. and Wilson, D. (2005) 'Theorising the puzzle that is Harold Shipman', The Journal of Forensic Psychiatry and Psychology, 16(4): 685-698.

Waller, S. and Deal, W.E. (2010) 'Introduction: Meditations of murder, or what is so philosophical about serial killers?' In S. Waller (Ed) Serial Killers: Being and Killing (p.p. 1-14). Oxford: WileyBlackwell.

Walsh, A. (2005) 'African Americans and serial killing in the media', Homicide Studies, 9, 271-91.

Webber, C. (2009) Psychology and crime, London: Sage.

Wilson, D. (2007) Serial Killers: Hunting Britons and their victims 1960-2006, Winchester: Waterside Press. 
Wilson, D., Jackson, C.A. and Rana, B. (2010a) 'Against the medical- psychological tradition of understanding serial killing by studying the killers: The case of BTK'. Amicus Journal, 22: 8-16.

Wilson, D., Tolputt, H., Howe, N. and Kemp, D. (2010b) 'When serial killers go unseen: The case of Trevor Joseph Hardy', Crime, Media, Culture, 6(2): 153-167.

Yardley, E. and Wilson, D. (2015) Female Serial Killers in Social Context: Criminological Institutionalism and the Case of Mary Ann Cotton, Bristol: Policy Press.

Yorker, B.C., Kizer, W., Lampe, P., Forrest, A.R.W., Lannan, J.M., and Russell, D.A. (2006) 'Serial murder by healthcare professionals', Journal of Forensic Science, 51: 1362-1371.

Zimbardo, P. (2009) The Lucifer Effect: How Good People Turn Evil, London: Rider.

\footnotetext{
' See Adjorlolo and Chan (2014) for a discussion on the abandonment of the specification of a 'cooling off' period in more recent scholarly definitions of serial murder.

ii See Canter and Youngs (2003) for discussion of the 'Hollywood effect' and the subsequent public acceptance of profiling as a credible and reliable tool for capturing the serial killer.

iii For example, in the UK Peter Sutcliffe was interviewed by the police on nine separate occasions between 1977 and 1980, but was released each time as not being the Yorkshire Ripper. Eventually, he was convicted of the murder of 13 women, and attempted murder of seven others in 1981. In the UK case of John Christie, his tenant Timothy Evans was wrongfully hanged in 1950 for the murder of his wife and child, suspicions only fell on Christie when four further bodies were found in his previous home in 1953. In the US, the FBI preoccupation with a white perpetrator in
} 
cases such as the Baton Rouge Murders (1992-2003) and the DC Snipers in 2002 seriously hindered the eventual apprehension of non-white offenders.

iv For further discussion see Lee's (2011) account of Myra Hindley; some of her supporters maintained her innocence even after further evidence of her complicity was made public. Also of interest is Master's (1997) account of Rosemary West, which seems surprisingly accepting of her claims of innocence.

${ }^{\mathrm{v}}$ It is worth noting here that Dennehy is one of those not uncommon cases that fail to fit an FBI definition, being neither a serial or mass killer, and the spree killer category being made obsolete in the FBI's 2005 definitional review.

${ }^{v i}$ She is in fact the only woman in the UK ever to be given this at the time of sentencing. Myra Hindley and Rose West were originally given different sentences that were later changed to a 'whole life' tariff. 